\title{
Prevalência de Leucemia Viral Felina (FeLV) e principais alterações hematológicas em felinos domésticos em Vila Velha, Espírito Santo
}

Prevalence of Feline Leukemia Virus (FeLV) and main hematological changes in domestic cats in Vila Velha, Espírito Santo

Prevalencia de Leucemia Viral Felina (FeLV) y principales alteraciones hematológicas en gatos domésticos en Vila Velha, Espirito Santo

Recebido: 02/04/2021 | Revisado: 07/05/2021 | Aceito: 11/05/2021 | Publicado: 28/05/2021

Heverton José Gonçalves

ORCID: https://orcid.org/0000-0002-0627-8826

Universidade Vila Velha, Brasil

E-mail: hjoseg12@hotmail.com

Carolina Magri Ferraz

ORCID: https://orcid.org/0000-0003-0390-3240

Universidade Vila Velha, Brasil

E-mail: carolinam_ferraz@hotmail.com

Emy Hiura

ORCID: https://orcid.org/0000-0002-6502-3292

Universidade Vila Velha, Brasil

E-mail: emyhiura@hotmail.com

Laysa Galvão Herzog

ORCID: https://orcid.org/0000-0003-4152-8488

Universidade Vila Velha, Brasil

E-mail: layzagherzog@ hotmail.com

Aldana Noelia Pucheta

ORCID: https://orcid.org/0000-0002-4552-1366

Universidade Vila Velha, Brasil

E-mail: aldananpucheta@hotmail.com

Larissa Claudino Ferreira

ORCID: https://orcid.org/0000-0003-0426-1091

Universidade Federal de Campina Grande, Brasil

E-mail: larissaclaudino.f@gmail.com

Vinícius Longo Ribeiro Vilela

ORCID: https://orcid.org/0000-0001-9891-7842 Instituto Federal de Educação, Ciência e Tecnologia da Paraíba, Brasil E-mail: vinicius.vilela@ifpb.edu.br

Fabio Ribeiro Braga

ORCID: https://orcid.org/0000-0003-2942-5785

Universidade Vila Vela, Brasil

E-mail: fabio.braga@uvv.br

\begin{abstract}
Resumo
O vírus da leucemia felina (FeLV- feline leukemia vírus) tem distribuição mundial e nos felinos domésticos a principal fonte de transmissão ocorre por meio da saliva. Assim, o contato direto ou indireto entre animais são causas preponderantes para a disseminação deste vírus. São escassos na literatura dados que direcionem o número de animais positivos no Espírito Santo, Sudeste do Brasil. Por isso, objetivou-se realizar o levantamento da prevalência de felinos domésticos FeLV positivos avaliar os parâmetros hematológicos presentes nestes animais infectados, assim como conhecimentos dos tutores sobre a doença. Foram analisados 70 prontuários de felinos domésticos testados para FeLV, no período de Janeiro de 2020 a Dezembro de 2020 e que foram atendidos no Hospital Veterinário da Universidade Vila Velha. Os felinos domésticos foram diagnosticados através do SNAP® FIV/FeLV Combo. Os dados hematológicos foram obtidos por meio de exames de hemograma e bioquímica sérica. Os resultados demonstraram uma ocorrência de 42,6\% de animais positivos para FeLV, sendo mais acometidos os machos $(18 / 30 ; 60 \%$; $\mathrm{P}<0,05)$ e animais com acesso à rua $(14 / 30 ; 46,7 \% ; \mathrm{P}<0,05)$. Todos os animais positivos apresentaram alguma alteração hematológica, como anemia, trombocitopenia, neutrofilia e linfopenia. Concluiu-se que é elevada a ocorrência de FeLV em gatos em Vila Velha, Espírito Santo, devendo medidas serem tomadas para intensificar as medidas de controle e profilaxia contra essa enfermidade.
\end{abstract}

Palavras-chave: Epidemiologia; Hematologia; Retrovírus. 


\begin{abstract}
The feline leukemia virus (FeLV) has a worldwide distribution and in domestic cats the main source of transmission occurs through saliva. Thus, direct or indirect contact between animals is a major cause for the spread of this virus. There are few data in the literature that direct the number of positive animals in Espírito Santo, Southeastern Brazil. Therefore, the objective was to carry out a survey of the prevalence of positive FeLV domestic cats to evaluate the hematological parameters present in these infected animals, as well as the tutors' knowledge about the disease. Seventy medical records of domestic cats tested for FeLV were analyzed, from January 2020 to December 2020 and were attended at the Veterinary Hospital of Universidade Vila Velha. Domestic cats were diagnosed using the SNAPß FIV / FeLV Combo. Hematological data were obtained by means of blood count and serum biochemistry tests. The results showed an occurrence of $42.6 \%$ of FeLV positive animals, with males being more affected $(18 / 30 ; 60 \%$; $\mathrm{P}<0.05)$ and animals with access to the street $(14 / 30 ; 46.7 \%$; $\mathrm{P}<0.05)$. All positive animals showed some hematological alteration, such as anemia, thrombocytopenia, neutrophilia and lymphopenia. It was concluded that the occurrence of FeLV in cats in Vila Velha, Espírito Santo is high, and measures should be taken to intensify the control and prophylaxis measures against this disease.
\end{abstract}

Keywords: Epidemiology; Hematology; Retrovirus.

\title{
Resumen
}

El virus de la leucemia felina (FeLV-virus de la leucemia felina) tiene una distribución mundial y en los gatos domésticos la principal fuente de transmisión se produce a través de la saliva. Por tanto, el contacto directo o indirecto entre animales es una de las principales causas de la propagación de este virus. Hay pocos datos en la literatura que dirijan el número de animales positivos en Espírito Santo, sureste de Brasil. Por tanto, el objetivo fue realizar una encuesta de prevalencia de gatos domésticos FeLV positivos para evaluar los parámetros hematológicos presentes en estos animales infectados, así como el conocimiento de los tutores sobre la enfermedad. Se analizaron setenta historias clínicas de gatos domésticos testeados para FeLV, desde enero de 2020 hasta diciembre de 2020 y fueron atendidos en el Hospital Veterinario de la Universidade Vila Velha. Los gatos domésticos fueron diagnosticados usando el SNAPß FIV / FeLV Combo. Los datos hematológicos se obtuvieron mediante hemograma y pruebas de bioquímica sérica. Los resultados mostraron una ocurrencia del $42,6 \%$ de animales positivos para FeLV, siendo los machos más afectados $(18 / 30 ; 60 \%$; P <0,05) y animales con acceso a la calle $(14 / 30 ; 46,7 \%$; $\mathrm{P}<0,05)$. Todos los animales positivos mostraron alguna alteración hematológica, como anemia, trombocitopenia, neutrofilia y linfopenia. Se concluyó que la ocurrencia de FeLV en gatos en Vila Velha, Espírito Santo es alta, y se deben tomar medidas para intensificar las medidas de control y profilaxis contra esta enfermedad.

Palabras clave: Epidemiologia; Hematologia; Retrovirus.

\section{Introdução}

O vírus da leucemia felina (FeLV) que pertence à família Retroviridae, gênero Gammaretrovirus, foi descrito em 1964 por William Jarrett e colaboradores ao encontrarem partículas virais ligadas à membrana de linfoblastos em um gato com linfoma (Jarret et al., 1964). O vírus possui envelope lipoprotéico e material genético composta por RNA de fita simples. O RNA é transcrito em DNA (pro-vírus) pela RNA polimerase viral Transcriptase reversa (RT) e é integrado ao genoma celular. No hospedeiro há uma divisão subseqüente, onde o pró-vírus servirá como um modelo para a produção de novas partículas virais no citoplasma das células infectadas (Hartmann, 2015).

De acordo com a literatura, tanto os felinos domésticos quanto os selvagens, são acometidos pela FeLV. Sendo este um retrovírus imunossupressor e oncogênico, está diretamente associado aos distúrbios degenerativos e mieloproliferativos. Esse agente viral tem uma distribuição predominantemente cosmopolita, e sua ocorrência está associada a alguns fatores de risco, como felinos de idade em torno de 1 a 5 anos, macho que seja semi domiciliar ou que habita em ambiente com alta densidade populacional e higienização precária (Ravazzollo \& Costa, 2007; Kennedy, 2015; Almeida et al., 2012; Hartmann, 2012).

Após a infecção, o vírus se replica em linfócitos e macrófagos do tecido linfoide regional, podendo se propagar para o resto do organismo através de linfócitos e monócitos (Sparkes, 1997). Dessa forma, ocorre a disseminação linfática com viremia transitória, e depois para o tecido linfoide sistêmico, ocorrendo infecção de células precursoras sanguíneas na medula óssea. Após o vírus atingir as células da medula óssea, que são de rápida replicação, a fase de viremia acontece dentro de algumas semanas ou meses (Rojko, 1979). Na segunda viremia é onde ocorre replicação viral em células epiteliais, inclusive 
aquelas das glândulas salivares, dos intestinos e das conjuntivas. Nas fases iniciais da doença, dependendo da imunidade do animal, da cepa e da quantidade de partículas virais, o animal pode se recuperar. Entretanto, como ocorre comprometimento da medula óssea pelo vírus, isso é pouco provável de ocorrer (Kennedy, 2015; Leal \& Villanova, 2015).

Dependendo do estado clínico e imunológico de cada felino contaminado pelo FeLV, há quatro possíveis desfechos para a infecção: progressiva, regressiva, abortiva e focal (Hofmann-Lehmann et al., 2008). A resposta do resultado da infecção envolve fatores que ainda não são totalmente esclarecidos, mas acredita-se que a carga inicial do pró-vírus pode influenciar nesse resultado, assim como a capacidade imunológica do hospedeiro em controlar a viremia (Hofmann-Lehmann et al., 2001).

Os métodos de diagnóstico para detecção viral nos felinos domésticos são realizados por meio de: exames clínicos, laboratoriais complementares e, principalmente, pela realização dos testes sorológicos como o método de ELISA, testes rápidos imunocromatográficos e a imunofluorescência indireta. Além disso, pode-se realizar o teste molecular de PCR (Reação em Cadeia da Polimerase), que detecta o DNA pró-viral do FeLV integrado em células sanguíneas (Almeida et al., 2016).

As alterações hematológicas não neoplásicas associadas ao FeLV incluem anemia (não-regenerativa ou regenerativa), síndrome da anemia mielodisplásica, anemia aplásica (pancitopenia), neutropenias persistentes e transitórias e anormalidades plaquetárias (trombocitopenia e anormalidades nas funções plaquetarias). De acordo com a maioria dos estudos, a anemia é a principal manifestação não neoplásica, ocorrendo em mais de 50\% dos felinos domésticos sintomáticos infectados por FeLV (Hartmann, 2011; Stützer et al., 2010).

Dados epidemiológicos constatam que FeLV está presente em vários países, variando de acordo com a região geográfica. No Brasil, foram realizados diversos estudos sorológicos e nos estados de São Paulo e Rio de Janeiro mostraram uma prevalência que varia de 12,5 a 20,3\%, respectivamente (Hagiwara et al., 1997; Souza et al., 2002). Já em Minas Gerais, um estudo sorológico realizado em abrigos de gatos em Belo Horizonte detectou prevalência de 22,5\% em fêmeas e de 10\%, em machos (Teixeira et al., 2007).

Apesar dos estudos em diversas Regiões do Brasil, são escassos os dados de FeLV em felinos domésticos no Espírito Santo. Por isso, o objetivo principal deste levantamento foi analisar a ocorrência do provírus da FeLV na população felina, assim como as principais alterações hematológicas causadas nesses animais positivos em Vila Velha, Espírito Santo.

\section{Metodologia}

Para execução do presente estudo retrospectivo e prospectivo, a fim de realizar uma avaliação de forma quantitativa, foram considerados 70 felinos domésticos, atendidos no período de janeiro de 2020 a dezembro de 2020, no setor de clínica médica de pequenos animais do Hospital Veterinário Professor Ricardo Alexandre Hippler, da Universidade Vila Velha (HOVET-UVV) (Pereira et al., 2018). Nesses animais, foi realizado o teste SNAP® FIV/FeLV Combo (IDEXX, Maine, EUA), possuíam os exames de hemograma, bioquímica sérica e tiveram o questionário aplicado aos proprietários. Foram utilizadas as fichas clínicas para a obtenção de detalhes sobre a anamnese e sintomatologia clínica destes animais com a finalidade de realizar uma avaliação qualitativa dos mesmos (Pereira et al., 2018).

Com o intuito de encontrar fatores associados à doença, foi aplicado um questionário aos tutores no momento da consulta, contendo informações acerca da idade e sexo do animal, e se era domiciliado ou semi-domiciliado.

Os dados hematológicos foram obtidos por meio de amostras de sangue total e soro, utilizados para a realização dos exames de hemograma e bioquímica sérica, respectivamente.

Para o hemograma, cerca de $0,5 \mathrm{~mL}$ de amostra de sangue foi coletada por punção da veia jugular e armazenada em microtubos contendo anticoagulante EDTA K2 (Modelo 3266NR, Vacuplast ${ }^{\circledR}$ ). Posteriormente, o sangue foi processado no equipamento URIT - 3000 Plus® por métodos de contagem automatizada, através de citometria de fluxo, na qual obteve-se os valores de eritrócitos, hemoglobina, hematócrito, volume corpuscular médio (VCM), concentração de hemoglobina 
corpuscular média (CHCM), leucócitos totais e plaquetas. Para visualização da morfologia das células sanguíneas e contagem da diferenciação dos leucócitos totais, foi confeccionada lâmina de esfregaço sanguíneo, coradas com panótico (Panotipo New Prove) e posteriormente analisadas em microscopia óptica na objetiva de 100 (aumento de 1000 vezes).

Os testes bioquímicos foram analisados no equipamento automatizado Humastar $80 \AA$, dosados e posteriormente avaliados os seguintes parâmetros: ureia, creatinina, as enzimas alanina aminotransferase (ALT), fosfatase alcalina (FA) e gamaglutamiltrasnferase (GGT) e as proteínas totais com suas frações albumina e globulina. Para este exame, amostra de sangue, entre 3 e $5 \mathrm{~mL}$, foi obtida também por meio de punção da veia jugular, contudo, foram armazenadas em tubos sem anticoagulante (Tubo com Ativador de Coágulo, Purevac®) para separação do soro.

Resultados foram transcritos para planilhas e realizadas análises descritivas. Para a comparação entre variáveis foram realizados os testes de Qui-quadrado e de Fisher em nível de significância de 5\%, utilizando o programa BioEstat 5.0 (Ayres et al., 2007).

\section{Resultados e Discussão}

Observou-se que 42,9\% (30/70) dos animais analisados eram FeLV positivos, obtendo-se uma porcentagem alta, comparando estudos de outras regiões do Brasil. Em Goiás, Centro-Oeste, foram testados 72 animais e apenas $2,77 \%$ resultaram em positivos (Lemos et al., 2019). Já em Porto Alegre, Rio Grande do Sul, dentre os 77 animais testados, 29,87\% foram positivos para FeLV (Finoketti, 2011). Os relatos apresentados acima demonstraram que a ocorrência do vírus está crescendo ao longo dos anos, sendo importante os estudos epidemiológicos para traçar medidas de controle e profilaxia para essas doenças infectocontagiosas.

De acordo com a predisposição por gênero, no presente trabalho, a prevalência foi mais alta em felinos machos (18/ $30 ; 60 \%$ ) do que em fêmeas (12/30; 40\%) (Tabela 1), corroborando com Hartmann (2012), que cita o gênero macho como um dos fatores de risco para ocorrência da infecção devido ao seu comportamento territorialista.

Tabela 1. Porcentagem de felinos testados para FeLV em Vila Velha, Espírito Santo, quando ao sexo, idade e acesso à rua

\begin{tabular}{ccccccccc}
\hline & & \multicolumn{2}{c}{ Sexo (\%) } & \multicolumn{2}{c}{ Idade (\%) } & & Acesso à rua $(\%)$ \\
\cline { 2 - 9 } FeLV & $\mathrm{N}$ & Macho & Fêmea & Filhote & Adulto & Não & Sim \\
Positivo & 30 & 60 & 40 & 46,7 & 53,3 & 53,3 & 46,7 \\
Negativo & 40 & 60 & 40 & 35 & 65 & 82,5 & 17,5 \\
\hline
\end{tabular}

Fonte: Autores.

Em relação à faixa etária, foram totalizados 46,7\% (14/30) dos felinos com até 1 ano de idade, 53,3\% (16/30) acima de 1 ano de idade, não demonstrando diferença estatística significativa $(P \geq 0,05)$. Esses achados estão de acordo com Cobucci et al. (2019).

Ainda de acordo com a Tabela 1, pode-se observar que dos 70 felinos participantes do trabalho, 46,7\% $(14 / 30 ; P<0,05)$ que tiveram acesso à rua foram positivos para FeLV. De acordo com Hartmann (2012), o "vigor" físico e maior atividade sexual são fatores predisponentes à infecção por FeLV.

No presente trabalho, a maioria dos felinos positivos apresentaram alguma alteração no hemograma. As principais alterações hematológicas observadas foram anemia 26,67\% (8/30), trombocitopenia 66,67\% (20/30), neutrofilia 16,67\% (5/30) e linfopenia 23,33\% (7/30) e corroborando com outros autores estão e estudos realizados (Hartmann, 2015; Lapinn, 2015; Kennedy, 2015; Almeida et al., 2016; Cobucci et al., 2019). De acordo com os achados na literatura, a anemia é a alteração 
hematológica não neoplásica mais importante que ocorre nos felinos FeLV positivo, sendo a anemia arregenerativa a mais comum, causada pelo efeito supressor do vírus na medula óssea, em consequência da infecção primária das células-tronco hematopoiéticas (Hartmann, 2015). Essa alteração está relacionada com o subgrupo FeLV-C (Lutz et al., 2009). Já a anemia regenerativa foi observada na maioria dos felinos, e com presença de alteração como: anisocitose, policromasia e metarrubrícitos (Thrall, 2015; Lacerda \& Hlavac, 2015). Esse tipo de anemia pode ocorrer devido infecções secundárias como consequência da imunossupressão que o vírus causa no animal e também porque o FeLV pode induzir uma resposta imunomediada levando ao desenvolvimento de anemia hemolítica imunomediada (Hartmann, 2015).

Os resultados da presente pesquisa ainda demonstraram achados como a linfopenia que foi observada em 23;33\% (7/30) dos casos e a neutropenia foi encontrada somente em 13,33\% (4/30) os felinos FeLV positivos. A linfopenia e neutropenia comumente são encontradas em gatos infectados pelo FeLV, porém, no presente estudo, a neutropenia teve uma frequência relativamente baixa. A linfopenia é resultante da replicação do vírus diretamente nos linfócitos caracterizada pela redução nos níveis de linfócitos CD4+, podem causar inversão de CD4/CD8. Por outro lado, a neutropenia ocorre devido a supressão de medula óssea ou destruição imunomediada de células pluripontecial, e geralmente é isolada ou em associação com outras citopenias (Hartmann, 2011; Hartmann, 2015). A linfopenia pode ocorrer também como resposta ao estresse resultando na liberação de cortisol induzindo a apoptose de linfócitos podendo alterar seus padrões de recirculação e também podendo causar alterações no hemograma como: agregado plaquetário e trombocitopenia, devido o nível alto de estresse durante a colheita do de sangue (Weiser, 2015). Além disso, a linfopenia e neutropenia causam imunossupressão, o que favorece as infecções oportunistas (Hofmann-Lehmann et al., 1997).

A neutrofilia ocorreu em 16,67\% (5/30) dos felinos positivos para FeLV provavelmente devido a co-infecções (bacteriana, fúngica, viral, parasitária) pois sabe-se que o subgrupo FeLV-T do vírus causa imunossupressão ocorrendo predisposição a infecções secundárias. A literatura discorre que a neutrofilia também pode ocorrer devido ao estresse ou induzida por glicocorticoide e pode ser fisiológica ou por liberação de epinefrina (Levy, 2010; Hartmann, 2015 \& Meizer, 2010).

A trombocitopenia foi a alteração hematológica mais relevante do presente trabalho acometendo 66,67\% (20/30) dos felinos positivos. Sabe-se que o vírus da leucemia felina tem a capacidade de induzir uma trombocitopenia imunomediada e também causa uma supressão da medula óssea tendo como consequência a diminuição da produção de plaquetas ou destruição imunomediada resultando em hemorragia ocorrendo distúrbios de coagulação secundariamente. Além das alterações na quantidade, observa-se também alterações no tamanho, formato e déficits da função das plaquetas (Hartmann, 2012; Hartmann, 2015; Lutz et al., 2009). Entretanto, os felinos apresentaram 55,26\% (21/38) de agregação plaquetária o que pode ter causado uma pseudotrombocitopenia ocasionado por estresse (Leonel et al., 2008). Em outros estudos, a trombocitopenia também foi observada no hemograma, porém com uma frequência menor que no presente trabalho (Ferreira et al., 2017). Todas as alterações hematológicas dos felinos negativos e positivos para FeLV estão demonstradas nas Figuras 1 e 2, respectivamente. 
Figura 1. Resultados dos parâmetros hematológicos de felinos positivos para FeLV, em Vila Velha, Espírito Santo.

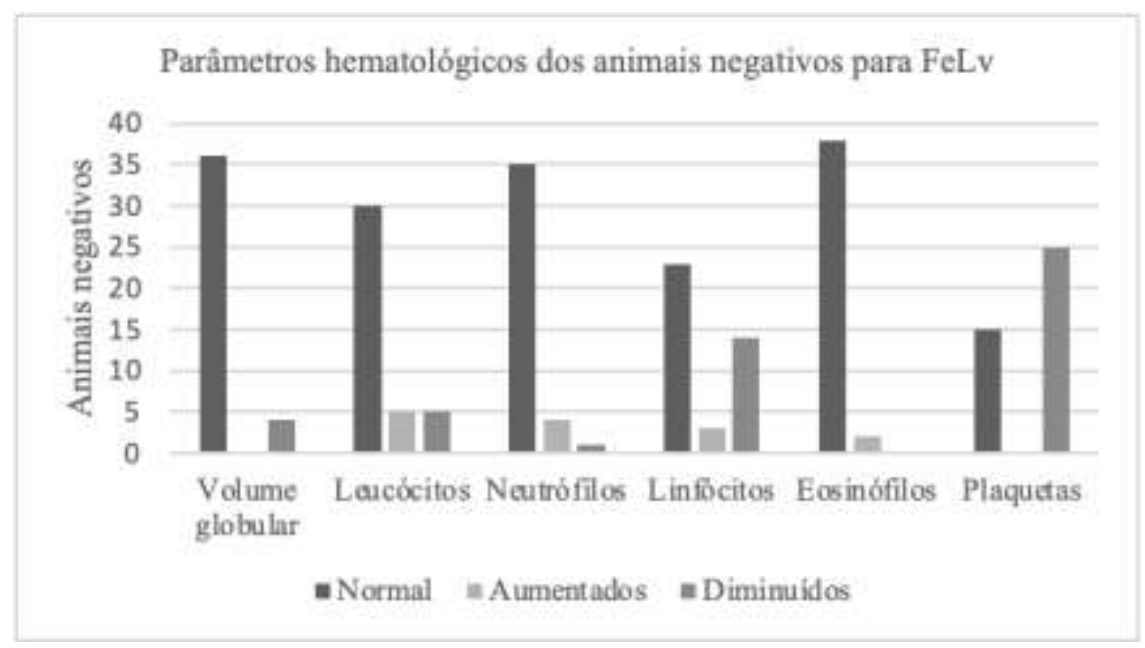

Fonte: Autores.

Figura 2. Resultados dos parâmetros hematológicos de felinos positivos para FeLv, em Vila Velha, Espírito Santo.

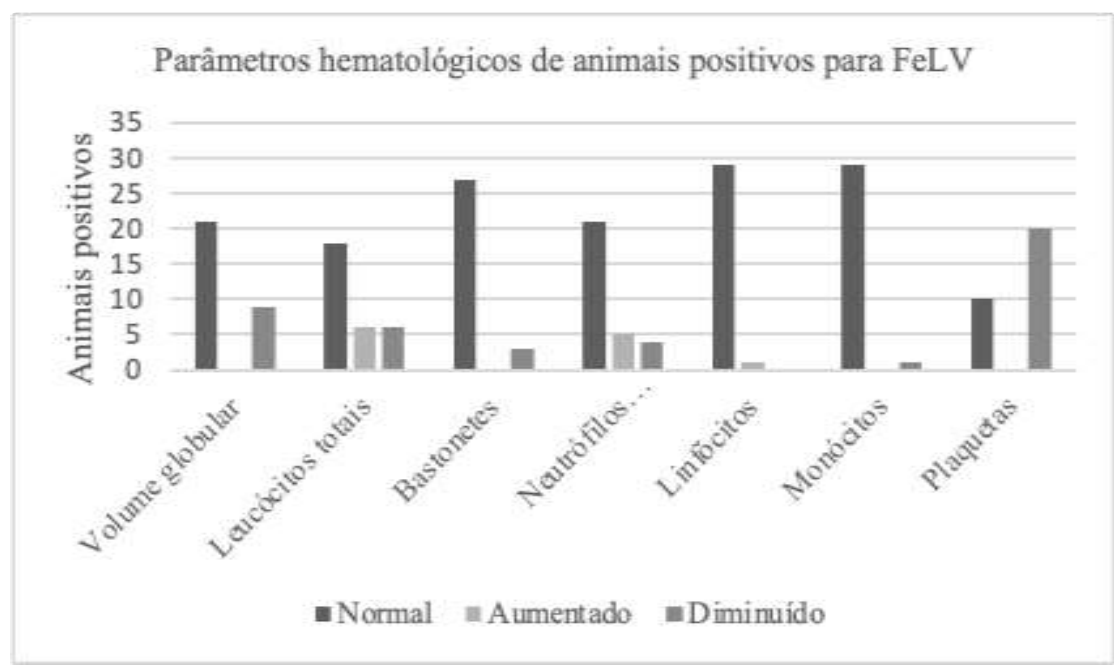

Fonte: Autores.

De acordo com a tabela 2, não foi apontada alteração significativa no perfil bioquímico renal de gatos infectados, resultado que corrobora com os achados de Arjona et al. (2000). Houve aumento da ALT em 26,7\%, sugerindo lesão superficial dos hepatócitos, que corroboram com estudos de Gleich e Hartmann (2009), os outros dados da bioquímica, como: FA, PPT, Albumina e Globulina, tiveram resultado a baixo do esperado. 
Tabela 2. Percentual e número dos animais $(\mathrm{n}=70)$ com ou sem alteração nos parâmetros bioquímicos positivos e negativos para FeLV no teste SNAP® FIV/FeLV Combo.

\begin{tabular}{|c|c|c|c|c|c|c|}
\hline \multirow{3}{*}{$\begin{array}{l}\text { Parâmetro } \\
\text { bioquímico }\end{array}$} & \multicolumn{6}{|c|}{ Resultado } \\
\hline & \multicolumn{2}{|c|}{ Normal } & \multicolumn{2}{|c|}{ Aumentado } & \multicolumn{2}{|c|}{ Diminuído } \\
\hline & FeLV+ & FeLV- & FeLV+ & FeLV- & FeLV+ & FeLV- \\
\hline Ureia & $73,3 \%(n=22)$ & $77,5 \%(n=31)$ & $26,7 \%(\mathrm{n}=8)$ & $22,5 \%(n=9)$ & 0 & 0 \\
\hline Creatinina & $86,7 \%(n=26)$ & $87,5 \%(n=35)$ & $3,3 \%(n=1)$ & $10 \%(\mathrm{n}=10)$ & $10 \%(\mathrm{n}=3)$ & $2,5 \%(\mathrm{n}=1)$ \\
\hline ALT & $73,3 \%(n=22)$ & $85 \%(n=34)$ & $26,7 \%(\mathrm{n}=8)$ & $15 \%(n=6)$ & 0 & 0 \\
\hline FA & $80 \%(n=24)$ & $62,5 \%(\mathrm{n}=25)$ & $13,3 \%(n=4)$ & $27,5 \%(\mathrm{n}=11)$ & $6,7 \%(n=2)$ & $10 \%(n=10)$ \\
\hline Proteínas totais & $93,3 \%(n=28)$ & $92,5 \%(n=37)$ & 0 & $7,5 \%(n=3)$ & $6,7 \%(n=2)$ & 0 \\
\hline Albumina & $73,3 \%(n=22)$ & $87,5 \%(n=35)$ & $6,7 \%(n=2)$ & $7,5 \%(n=3)$ & $20 \%(n=6)$ & $5 \%(n=2)$ \\
\hline Globulina & $90 \%(n=27)$ & $92,5 \%(n=37)$ & $3,3 \%(n=1)$ & $7,5 \%(n=3)$ & $6,7 \%(n=2)$ & 0 \\
\hline
\end{tabular}

Fonte: Autores.

\section{Conclusão}

Concluiu-se que há um alto nível de infecção por FeLV entre os felinos domésticos em Vila Velha, Espírito Santo. É notória a importância da realização de exames hematológicos, sendo estes capazes de demonstrar alterações mesmo nos pacientes assintomáticos, auxiliando na detecção dessa infecção na rotina clínica. Devem ser intensificadas medidas de controle e profilaxia para mitigar a transmissão desta enfermidade entre os felinos na área estudada.

Sugere-se também que sejam realizados novos estudos que abranjam diferentes municípios, para que se tenha um percentual mais abrangente dos casos de FeLV no estado do Espirito Santo.

\section{Referências}

Almeida, N. R., Soares, L.C. \& Wardini, A. B. (2016). Alterações clínicas e hematológicas em felino doméstico domésticos naturalmente infectados pelo Vírus da Leucemia Felina (FeLV). Revista de Saúde. 7(1): 27-32.

Almeida, T. M., Souza Filho, R. P., Rodrigues, I. L., Cruz, L. O., Rodrigues, A. P. R. \& Silva, I. N. G. (2014). Linfoma leucemizado em felino coinfectado com os vírus da imunodeficiência felina e da leucemia felina: relato de caso. Arquivo brasileiro de Medicina Veterinária e Zootecnia. 8(4): $36-37$.

Arjona, A., Escolar, E., Soto, I., Barquero, N., Martin, D. \& Gomez-Lucia, E. (2000) Seroepidemiological survey of infection by feline leukemia virus and immunodeficiency virus in Madrid and correlation with some clinica aspects. Journal of Clinical Microbiology. 38(6):3448-3449.

Ayres, M., Ayres, J.R.M., Ayres, D.L. \& Santos, A.S. (2003). Aplicações estatísticas nas áreas de ciências biológicas. Sociedade Civil Mamirauá, Belém, p 290 .

Chen, H., Bechtel, M. K., Shi, Y., Phipps, A., Mathes, L. E., Hayes, K. A. \& Roy-Burman, P. (1998). Pathogenicity induced by feline leukemia virus, Rickard strain, subgroup A plasmid DNA (pFRA). Journal of Virology. 72(9): 7048-7056.

Cobucci, G. C. (2014). Fatores de risco e sintomatologia clínica associados à infecção pelo vírus da Leucemia Felina: estudo caso-controle no Hospital Veterinário da Universidade Federal de Viçosa. Trabalho de conclusão Residência em Medicina Veterinária.

Ferreira, G. S., Masson, G. C. I. H., Galvão, A. L. B., Léga, E. \& Pinto, M. L. (2017). Vírus da imunodeficiência felina: um desafio clínico. Nucleus animalium. 3 (1): 85-98.

Finoketti, F. (2011). Ocorrência dos vírus da imunodeficiência felina (FIV) e leucemia felina (FeLV) em felinos no município de Porto Alegre, RS. Trabalho de conclusão de curso de graduação, Instituto de Ciências Básicas da Saúde da Universidade Federal do Rio Grande do Sul, Porto Alegre, Rio Grande do Sul, Brasil. 
Gleich, S. \& Hartman, K. (2021). Hematology and serum biochemistry of feline immunodeficiency virus-infected and feline leukemia virus infected cats. Journal of Veterinary Internal Medicine. 23(3): 552-558.

Hagiwara, M. K., Jorge, J. J. \& Stricagnolo, C. Infecção pelo vírus da leucemia felina em gatos de diversas cidades do Brasil. ClÍnica Veterinária. 12(66): 2007.

Hartmann, K. (2006). Feline leukemia virus infection. Infectious disease of the dog and cat. 13(3): 105-131.

Hartmann, K. (2011). Clinical aspects of feline immunodeficiency and feline leukemia virus infection. Veterinary Immunology and Immunopathology. 143(3): $190-201$.

Hartmann, K. (2012). Clinical Aspects of Feline Retroviruses: A Review. Viruses. 4(11): 2684- 2710.

Hartmann, K. (2015). Infecção pelo Vírus da Leucemia Felina. In: GREENE, C.E. Doenças Infecciosas em cães e felinos domésticos. Guanabara Koogan. 333 (11): $113-143$.

Jarrett, O., Golder, M. C., Toth, S., Onions, D. E. \& Stewart, M. F. (1984). Interaction between feline leukaemia virus subgroups in the pathogenesis of erythroid hypoplasia. International Journal of Cancer. 34 (2): 283-288.

Lehmann, R. H. (2021). Feline leukaemia virus infection. Feline leukaemia virus infection: http://www.abcdcatsvets.org/feline-leukaemia-virus-infection/.

Levy, J., Crawford, C., Hartmann, K., Lehmann, R. H., Little, S., Sundahl, E. \& Thayer, V. (2008). American Association of Feline Practitioners' Feline Retrovirus Management Guidelines. Journal of Feline Medicine and Surgery. 10 (3): 300-316.

Meinerz, A.R.M. (2010). Frequência do virus da leucemia felina (VLFe) em felinos domésticos (Felis catus) semidomiciliados nos municípios de Pelotas e Rio Grande. Ciência Animal Brasileira. 11 (1): 90-93.

Norsworthy, G. D., Crystal, M. A., Grace, S. F. \& Tilley, L. P. (2011). The Feline Patient. Wiley-Blackwell. 47 (4): $106-107$.

Pereira, A. S., Shitsuka, D. M., Parreira, F. J. \& Shitsuka, R. (2018). Metodologia da pesquisa científica. 1(1):67-69.

Ravazzolo, A. P. \& Costa, U.M. (2007). Retroviridae. In: FLORES, E.F. (Ed.). Virologia veterinária. 31(1): 831-835.

Rojko, J. L. (1979). Pathogenesis of experimental feline leukemia virus infection. Journal of the National Cancer Institute. 63(3): 759-768.

Souza, H. J. M., Teixeira, C. H. R. \& Graça, R. F. S. (2002). Estudo epidemiológico da infecção pelo vírus da leucemia e/ou imunodeficiência felina, em gatos domésticos do município do Rio de Janeiro. Clínica Veterinária. 36(1): 14-21.

Sparkes, A. H. (1997). Feline leukemia virus: a review of immunity and vaccination. Journal of Small Animal Practice. 38 (5): $187-194$.

Stutzer, B. (2010). Role of latent feline leukemia virus infection in non regenerative cytopenias of cats. Journal of Veterinary Internal Medicine. 24 (1): 192197.

Teixeira, B. M. (2007) Ocorrência do vírus da imunodeficiência felina e do vírus da leucemia felina em gatos domésticos mantidos em abrigos no município de Belo Horizonte. Arquivo Brasileiro de Medicina Veterinária e Zootecnia. 59 (4): 939-947. 